\title{
Reliability and methodology of quantitative assessment of harvested and unharvested patellar tendons of $A C L$ injured athletes using ultrasound tissue characterization
}

\author{
Carla S. Pereira ${ }^{1,2^{*}}$ (D), Rafael C. G. Santos ${ }^{1}$, Rod Whiteley ${ }^{1}$ and Taija Finni ${ }^{2}$
}

\begin{abstract}
Background: Ultrasound tissue characterization (UTC) imaging has been previously used to describe the characteristics of patellar and Achilles tendons. UTC imaging compares and correlates successive ultrasonographic transverse tendon images to calculate the distribution of four color-coded echo-types that represent different tendon tissue types. However, UTC has not been used to describe the characteristics of patellar tendons after anterior cruciate ligament reconstruction (ACLR). The aim of this cross-sectional study was to assess the intra and inter-rater reliability of the UTC in unharvested and harvested patellar tendons of patients undergoing ACLR.
\end{abstract}

Methods: Intra and inter-rater reliability of both UTC data collection and analysis were assessed. Ten harvested and twenty unharvested patellar tendons from eighteen participants were scanned twice by the same examiner. Eleven harvested and ten unharvested patellar tendons from sixteen participants were scanned and analyzed twice by two different examiners. Twenty harvested and nineteen unharvested patellar tendons from twenty-three participants were analyzed twice by two examiners.

Results: Quantification of the proportion of echo-types I, II, II and IV in the areas of interest: (1) patella apex, (2) proximal tendon, (3) mid tendon, (4) distal tendon, and overall tendon of harvested and unharvested patellar tendons all displayed excellent intra-rater reliability (ICC 2 : 0.94 to 0.99), excellent inter-rater reliability for harvested and unharvested patellar tendon scanning and analysis (ICC $2,1: 0.89$ to 0.98 ), and excellent inter-rater reliability for analysis (ICC $2,1: 0.95$ to 0.99 ). Intra-rater reliability for the measure of volume was good (ICC $2,1: 0.69$ harvested, 0.67 unharvested), whilst mixed results were observed for the measure of mid tendon thickness (ICC $2,1: 0.88$ harvested, 0.57 unharvested). Inter-rater reliability for scanning and analysis was good for volume (ICC $2,1: 0.67)$ and excellent for thickness (ICC $2,1: 0.97)$, while the inter-rater reliability for analysis was fair to poor for volume (ICC $2,1: 0.59$ harvested, 0.30 unharvested), and excellent to poor for mid tendon thickness (ICC $2,1: 0.85$ harvested, 0.24 unharvested).

Conclusion: UTC imaging is a reliable tool to characterize the quality of most aspects of unharvested and harvested patellar tendons in subjects undergoing ACLR.

Keywords: Anterior cruciate ligament, Echo-types distribution, Graft, Tendon quality, UTC

\footnotetext{
* Correspondence: carla.pereira@aspetar.com

${ }^{1}$ ASPETAR Orthopaedic and Sports Medicine Hospital, Sports City Street,

Inside Aspire Zone, Al Buwairda St, DohaPO Box 29222Qatar

${ }^{2}$ Faculty of Sport and Health Sciences, Biology of Physical Activity,

Neuromuscular Research Center, University of Jyväskylä, Jyväskylä, Finland
}

(c) The Author(s). 2019 Open Access This article is distributed under the terms of the Creative Commons Attribution 4.0 International License (http://creativecommons.org/licenses/by/4.0/), which permits unrestricted use, distribution, and reproduction in any medium, provided you give appropriate credit to the original author(s) and the source, provide a link to the Creative Commons license, and indicate if changes were made. The Creative Commons Public Domain Dedication waiver (http://creativecommons.org/publicdomain/zero/1.0/) applies to the data made available in this article, unless otherwise stated. 


\section{Background}

Ultrasound tissue characterization (UTC) has been used to assess the integrity of tendon structure in animals and humans. [1-8] UTC captures contiguous transverse ultrasound images over the length of the tendon and semi- quantifies the stability of the echotexture over successive transverse ultrasonographic images. [1-3] Four different echo-types have been proposed to discriminate the underlying tendon tissue types; type $\mathrm{I}=$ intact and aligned collagen bundles; type II = discontinuous, swollen and wavy collagen bundles; type III = loose matrix; and type IV = amorphous matrix. [2] The validation of this method to date has originally been based on histopathologic studies of the superficial digital flexor tendons of horses, $[1,2,9]$, and subsequently the use of UTC has expanded to human tendons. $[3,5,6]$ Reliability of UTC imaging in both healthy and pathological tendons has demonstrated high intra- and inter-observer reproducibility for both acquisition and analysis. [3, 10]

Studies using UTC imaging have documented alterations in tendon appearance in the presence of clinically diagnosed Achilles tendinopathy, [3, 7, 11-18] patellar tendinopathy, $[11,18]$ systemic disease such as diabetes, [19] after platelet-rich plasma (PRP) injection, [4] and after different therapeutic exercise programs. $[5,6,12,14]$

Anterior cruciate ligament (ACL) injuries are one of the most devastating injuries encountered in sports medicine due to the likely requirement of surgery, and the extended recovery and rehabilitation period following the injury. Where surgical reconstruction of the injured ligament is decided (ACL reconstruction - ACLR), surgeons may choose from a range of possible grafts to repair the torn ligament, including allograft - from cadavers or synthetic, and autograft - when either a portion of the quadriceps tendon, hamstrings tendons (Hst), or frequently, the patellar tendon (BTB) is harvested. [20] BTB autograft has garnered increased attention and popularity in recent decades, which has been attributed to the hypothesis that BTB grafts provide superior post-operative stability via its bone-tobone attachments [21, 22]. However, BTB grafts have been associated with increased donor site morbidity, particularly anterior knee pain and quadriceps weakness have been reported [23-25]. Potentially increased understanding of the effects of BTB grafts on tendon structure may help negate the potential side effects of this surgical approach. While UTC has documented reliability and normative data for typical anterior knee pain populations (echo-type I (\%) $58 \pm 7$; echo-type II (\%) $34 \pm 5$; echo-types III (\%) $6 \pm 4$; echo-type IV (\%) $3 \pm 2$ ) [10], there are no normative or reliability data for those undergoing ACLR using a BTB graft. To establish the utility of interventions for these populations and to understand meaningful changes of the tendon tissue characteristics as they relate to symptoms, reliability and normative data need to be documented in this population. Therefore, the aim of the current study was to assess the intra- and inter-rater reliability of UTC imaging in harvested patellar tendons after ACLR and to provide normative values for this population.

\section{Methods \\ Participants}

The patellar tendons assessed in this study were from participants who sought conservative or surgical treatment for an ACL injury at Aspetar, Orthopaedic and Sports Medicine Hospital, Doha, Qatar. Thirty-seven male athletes registered within Qatar's sporting federations regularly attending Aspetar Orthopaedic and Sports Medicine Hospital for rehabilitation following ACL injury and/or ACLR during the period of February to August 2018 were invited to participate in the study. Patients were deemed suitable to participate in the study if they were: male, had a diagnosed ACL tear confirmed by magnetic resonance imaging or a previously performed ACLR, and agreed to take part in one or more phases of this study and to be assessed by different examiners and/or on different days (Table 1).

Written informed consent was obtained from each participant or legal guardian. Ethical approval was obtained by ethical committee of the Anti-Doping Laboratory Qatar Research Office (2017000227).

\section{Ultrasound tissue characterization (UTC)}

UTC imaging utilizes a $5-12 \mathrm{MHz}$ ultrasound (US) transducer (SmartProbe 12 L5, Terason 2000, Teratech, USA) fixed in a transverse position into a $12 \mathrm{~cm}$ tracking device (UTC Tracker, UTC imaging, Netherlands), allowing the capture and storage of a sequence of transverse images of the tendon at regular intervals of 0.02 $\mathrm{cm}$ (Fig. 1). Participants lay supine with their knees flexed at approximately $100^{\circ}$ and their feet parallel resting on the plinth. Coupling gel was applied between the US probe and the stand-off pad, and between the standoff pad and the skin to optimize contact. The examiners held the UTC tracker device resting with full contact on participant's anterior knee, parallel to the long axis of the patellar tendon (Fig. 2). The US transducer was placed initially over the apex of the patella and manually moved down to ensure the patellar tendon was centrally located on the transverse view in the UTC acquisition software. Once a good position was visually affirmed, the data acquisition was initiated. The US transducer then moved down the track driven by a motor, from proximal to distal, resulting in a total of 598 sequential transverse images acquired in $45 \mathrm{~s}$. With these scans the UTC algorithm creates a 3D block of the scanned area allowing additional reconstructed coronal and sagittal views (Fig. 3). A scan was considered satisfactory and included for analysis when the upper surface of the patella and 
Table 1 Participants' graft type, sport, patellar tendon investigated and participation time in the different analysis

\begin{tabular}{|c|c|c|c|c|c|c|c|c|c|c|}
\hline \multirow[t]{2}{*}{$\begin{array}{l}\text { Participant's } \\
\text { number }\end{array}$} & \multirow[t]{2}{*}{ Graft } & \multirow[t]{2}{*}{ Sports } & \multirow{2}{*}{$\begin{array}{l}\text { Intra-rater } \\
\text { Harvested } \\
\text { Involved }\end{array}$} & \multicolumn{2}{|c|}{$\begin{array}{l}\text { Intra-rater } \\
\text { Unharvested }\end{array}$} & \multicolumn{2}{|c|}{$\begin{array}{l}\text { Inter-rater Acquisition } \\
\text { \& Analysis }\end{array}$} & \multirow{2}{*}{$\begin{array}{l}\text { Inter-rater } \\
\text { Harvested } \\
\text { Involved }\end{array}$} & \multicolumn{2}{|c|}{$\begin{array}{l}\text { Inter-rater } \\
\text { Unharvested }\end{array}$} \\
\hline & & & & Involved & Uninvolved & Involved & Uninvolved & & Involved & Uninvolved \\
\hline 1 & Hst & Football & & $10.5 \mathrm{M}$ & & & & & $10.5 \mathrm{M}$ & \\
\hline 2 & BTB Revision & Football & & & & $3 \mathrm{M}$ & & $3 M$ & & \\
\hline 3 & BTB & Table tennis & & & & $6 \mathrm{~W}$ & & $6 \mathrm{~W}$ & & preop \\
\hline 4 & BTB & Futsal & & & & & & & preop & preop \\
\hline 5 & BTB & Football & $1 Y$ & & & & & $1 Y$ & & \\
\hline 6 & BTB & Football & & & & preop & preop & & & \\
\hline 7 & Hst & Volleyball & & & & preop & & & & \\
\hline 8 & BTB & Football & & & & $6 \mathrm{M}$ & & $6 \mathrm{~W}, 6 \mathrm{M}$ & preop & \\
\hline 9 & BTB & Football & & & & & $6 \mathrm{M}$ & & & \\
\hline 10 & Allograft & Basketball & & & & $6 \mathrm{M}$ & & & & \\
\hline 11 & BTB & Handball & & & & & & $6 \mathrm{~W}, 6 \mathrm{M}$ & preop & \\
\hline 12 & BTB Revision & Football & $6 \mathrm{~W}$ & & & & & $6 \mathrm{~W}$ & & \\
\hline 13 & BTB Revision & Football & & & $3 \mathrm{M}, 4.5 \mathrm{M}$ & & & & & $4.5 \mathrm{M}$ \\
\hline 14 & Conservative & Football & & & & preop & & & & \\
\hline 15 & BTB & Handball & & & & $6 \mathrm{M}$ & & & & \\
\hline 16 & Hst & Football & & $6 \mathrm{M}$ & $6 \mathrm{M}$ & & & & $6 \mathrm{M}$ & $6 \mathrm{M}$ \\
\hline 17 & BTB & Football & $9 \mathrm{M}$ & & $9 M$ & & & $9 \mathrm{M}$ & & $9 \mathrm{M}$ \\
\hline 18 & BTB & Football & & & & & & & preop & preop \\
\hline 19 & BTB & Football & $9 \mathrm{M}$ & & $10.5 \mathrm{M}$ & & & $9 M$ & & $10.5 \mathrm{M}$ \\
\hline 20 & BTB & Football & $7.5 \mathrm{M}$ & & & & & $7.5 \mathrm{M}$ & & \\
\hline 21 & Hst & Handball & & $4.5 \mathrm{M}$ & $4.5 \mathrm{M}$ & & & & $4.5 \mathrm{M}$ & $4.5 \mathrm{M}$ \\
\hline 22 & Hst & Football & & $6 \mathrm{M}$ & $6 \mathrm{M}$ & & & & & $6 \mathrm{M}$ \\
\hline 23 & BTB & Hockey & & & & $4.5 \mathrm{M}$ & $4.5 \mathrm{M}$ & & & \\
\hline 24 & BTB & Football & $4.5 \mathrm{M}$ & & & & & $4.5 \mathrm{M}$ & & \\
\hline 25 & BTB & Football & $3 \mathrm{M}$ & & $3 \mathrm{M}$ & & & $3 \mathrm{M}$ & & $3 \mathrm{M}$ \\
\hline 26 & BTB & Football & & & & $6 \mathrm{~W}$ & $6 \mathrm{~W}$ & & & \\
\hline 27 & Hst & Cycling & & $6 \mathrm{~W}$ & $6 \mathrm{~W}$ & & & & & \\
\hline 28 & BTB & Handball & & & & $6 \mathrm{M}$ & $6 \mathrm{M}$ & $6 \mathrm{~W}, 6 \mathrm{M}$ & preop & \\
\hline 29 & BTB & Basketball & $6 \mathrm{~W}$ & & $6 \mathrm{~W}$ & & & $6 \mathrm{~W}$ & & $6 \mathrm{~W}$ \\
\hline 30 & BTB & Football & $6 \mathrm{~W}$ & & $6 \mathrm{~W}$ & & & $6 \mathrm{~W}$ & & \\
\hline 31 & BTB & Rugby & & & & & preop & & & \\
\hline 32 & Hst & Handball & & $3 \mathrm{M}$ & & & & & & \\
\hline 33 & BTB & Sky diving & & & & $6 \mathrm{~W}$ & & & & \\
\hline 34 & BTB & Football & & & & $6 \mathrm{~W}$ & $6 W$ & $6 \mathrm{~W}$ & & \\
\hline 35 & BTB & Football & $3 \mathrm{M}$ & & $3 M$ & & & $3 \mathrm{M}$ & & \\
\hline 36 & Conservative & Football & & preop & preop & & & & & \\
\hline 37 & BTB & Football & & & & $3 \mathrm{M}$ & & $3 \mathrm{M}$ & & \\
\hline
\end{tabular}

"preop": pre-operation. " $\mathrm{W}$ ", " $\mathrm{M}$ ", and " $\mathrm{Y}$ " denote weeks, months, and years post-operative respectively BTB Bone patellar tendon bone graft, Hst Hamstring graft

tibial tuberosity were at the same level with the patellar tendon horizontal and taut on the sagittal view of the UTC acquisition software, and the patella and tibial tuberosity were aligned longitudinally with the patellar tendon vertically displayed in the coronal view of the UTC acquisition software (Fig. 3). The patellar tendons of participants whose UTC scans did not meet the above criteria (mostly due to painful limited knee flexion post- 


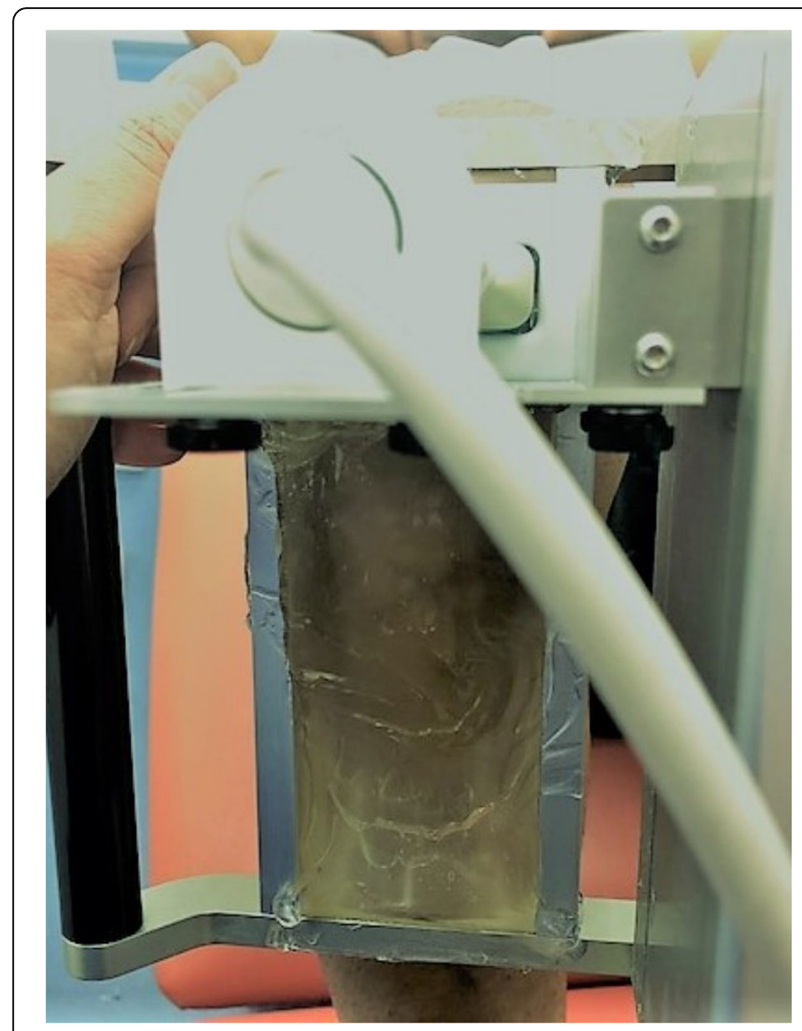

Fig. 1 Superior view of UTC transducer transversely fixed into tracking device for scanning a right patellar tendon

operatively) were excluded. Due to the presence of swelling and thickness of the harvested patellar tendon we adopted the factory preset of the UTC imaging software for patellar tendons (PT_UTC_VH4028) for medium size participants, with US parameters standardized as: $12 \mathrm{MHz}$, focus at $2.8 \mathrm{~cm}$, and depth of $4 \mathrm{~cm}$. For these settings each pixel unit can be considered as equivalent to $1.0 \mathrm{~mm}$. In all cases the right knee was scanned first.

\section{UTC data analysis and processing}

All analyses were performed on the UTC analyzer v.2.0.2 using a window size 17. Two examiners scanned the same patellar tendons on the same day. Only one examiner scanned the same patellar tendons twice, 1 day apart. Subsequently software analysis of the same patellar tendons was performed on different days to avoid any possibility of bias in this phase. For the analysis, the margin of the patellar tendon (contour) was manually traced in the transverse images of the tendon creating at least 10 sections along the patellar tendon length to quantify the whole tendon structure (Fig. 4). The first contour of each tendon was drawn from the notch of the tibia. This contour determines the last (most distal) transverse image included in the patellar tendon characterization analysis. The examiner ensured longitudinal alignment between the notch of the tibia and the

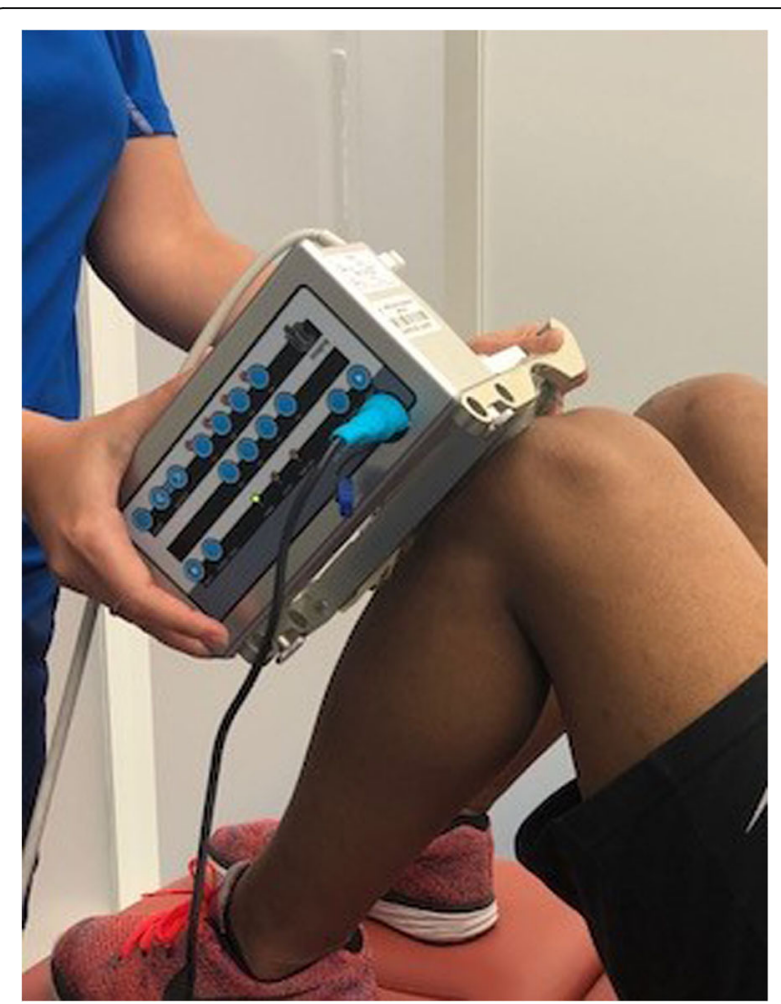

Fig. 2 Lateral view of UTC tracking device showing silicone pad in contact with left patellar tendon

patellar apex to draw this contour. The second contour was drawn from the first transverse image immediately distal to the patellar apex. This is the first area of interest, set as reference mark 1 in the UTC acquisition software, and is the first transverse image included in the characterization analysis which defines the beginning of the patellar tendon length measurement. Twenty-six images distal to reference mark 1, another contour was drawn (2nd area of interest = reference mark 2) representing the proximal area of the patellar tendon $(0.52 \mathrm{~cm}$ distal from patellar apex). The 3rd area of interest or mid tendon (reference mark 3) was drawn 51 images distal from reference mark $2(1.54 \mathrm{~cm}$ distal from patellar apex). $[8,26]$ Additionally, at $75 \%$ of the distance between the reference mark 1 and the notch of the tibia (last contour), a fourth contour was drawn (4th area of interest = reference mark 4) to characterize the distal part of the patellar tendon (Fig. 5a). Between reference marks 2 and 3, another two contours were drawn approximately $0.5 \mathrm{~cm}$ apart. Between reference marks 3 and 4, additional contours were drawn at approximately $0.5 \mathrm{~cm}$ intervals, and between reference mark 4 and the notch of the tibia another contour was drawn. (Note that each additional contour provided to the software reduces the amount of interpolation required to depict the patellar tendon.) Only the transverse images between the 


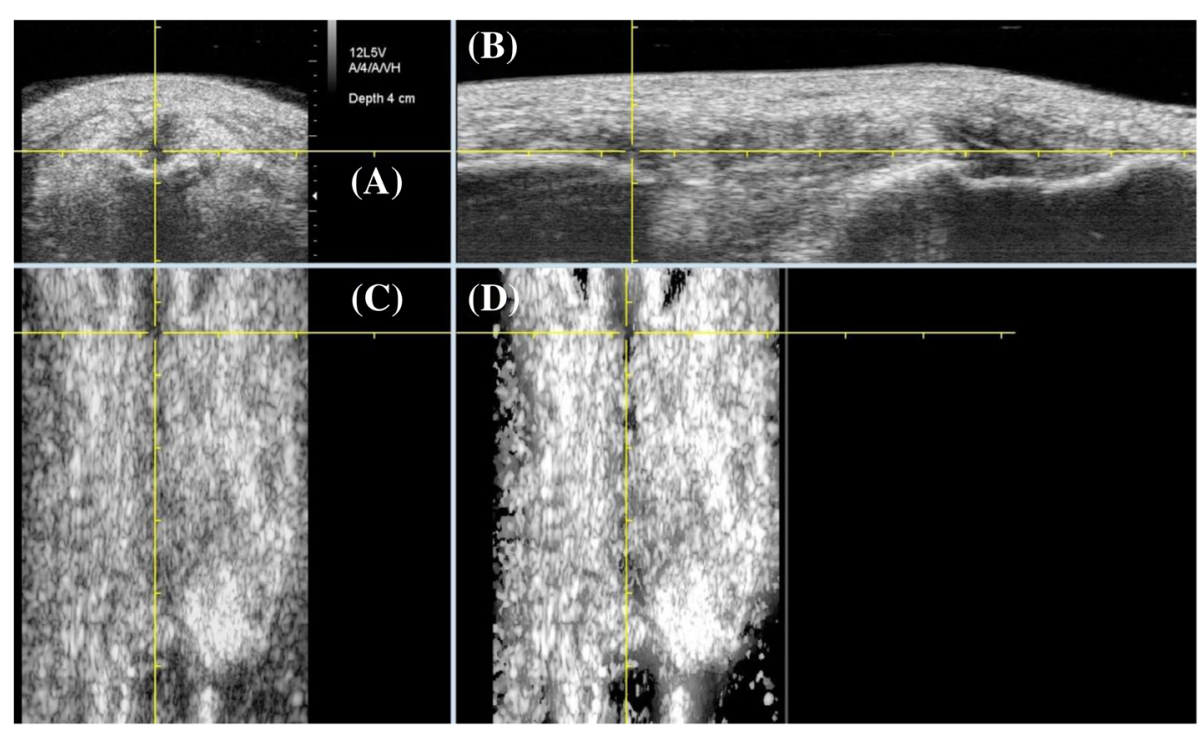

Fig. 3 Transverse (a), sagittal (b), and coronal (c \& d) views of a harvested patellar tendon. The cross-hair is placed in the center of the harvested region (3A) at the distal pole of the patella (3B). Horizontal line ensures that patella and tibia tuberosity are at the same level (3B). The vertical lines in (3C) and (3D) allow confirmation that patella apex and tibia tuberosity are aligned. Horizontal and vertical alignment are requirements for a scan to be considered of a satisfactory quality to be saved and included for analysis

patellar apex and the notch of the tibia were considered in the characterization analysis of the patellar tendon. Measurement of thickness of the mid tendon was done manually using the measuring tool of the UTC imaging software (Fig. 5a). The distance in centimeters between the first and last contours represents the length of the patellar tendon (Fig. 5b).

The UTC algorithm quantifies the proportion of echotypes in each specific area of interest, (1) patellar apex, (2) proximal tendon, (3) mid tendon, (4) distal tendon, and (5) overall tendon (all the tendon information between the first and last contours, patellar apex and notch of the tibia, respectively). Four sub-types of tendon are classified according to 4 primary tendon features appearing on grayscale ultrasound images: continuity, integrity and alignment of the collagen tendon bundles, and brightness [2]. In essence, alignment is measured by the degree of variation from a true, straight line of a series of pixels within the window being examined. Variation in brightness is estimated by comparing adjacent pixels on their grayscale value - i.e. the representation of the pixel on a scale from complete black through to bright white. The echo-type I (green) is generated by intact and aligned collagen bundles. These collagen bundles appear

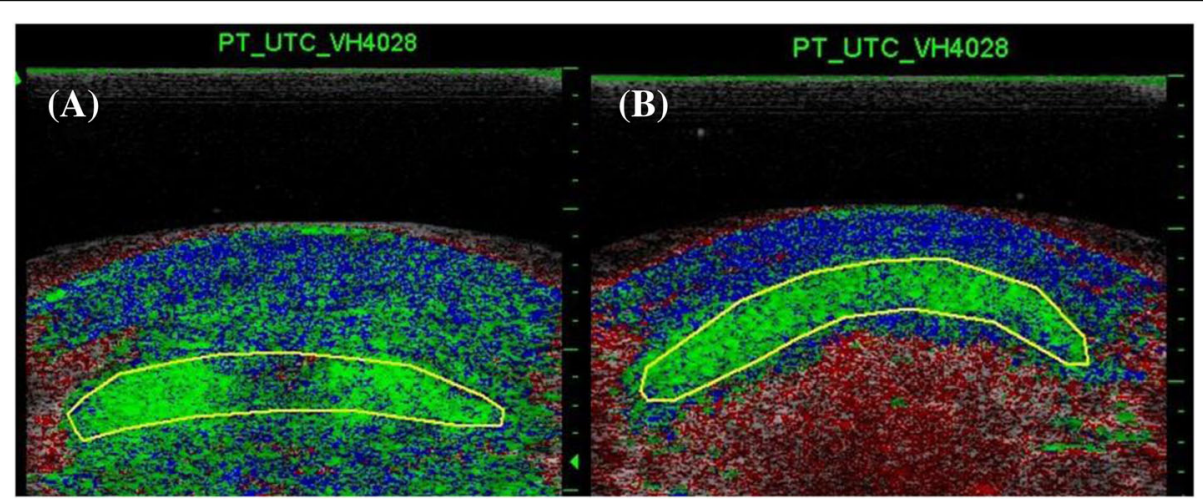

Fig. 4 Example of contours drawn in cross-sectional view in harvested (a) and unharvested (b) patellar tendons. Echo-types I are shown as green, echotype 2 as blue, echo-type III as red, and echo-type 4 as black. Note that only the area inside the marked yellow circumference is quantified as patellar tendon, and it is in this area that all calculations regarding relative percentages of different echo-types are made 

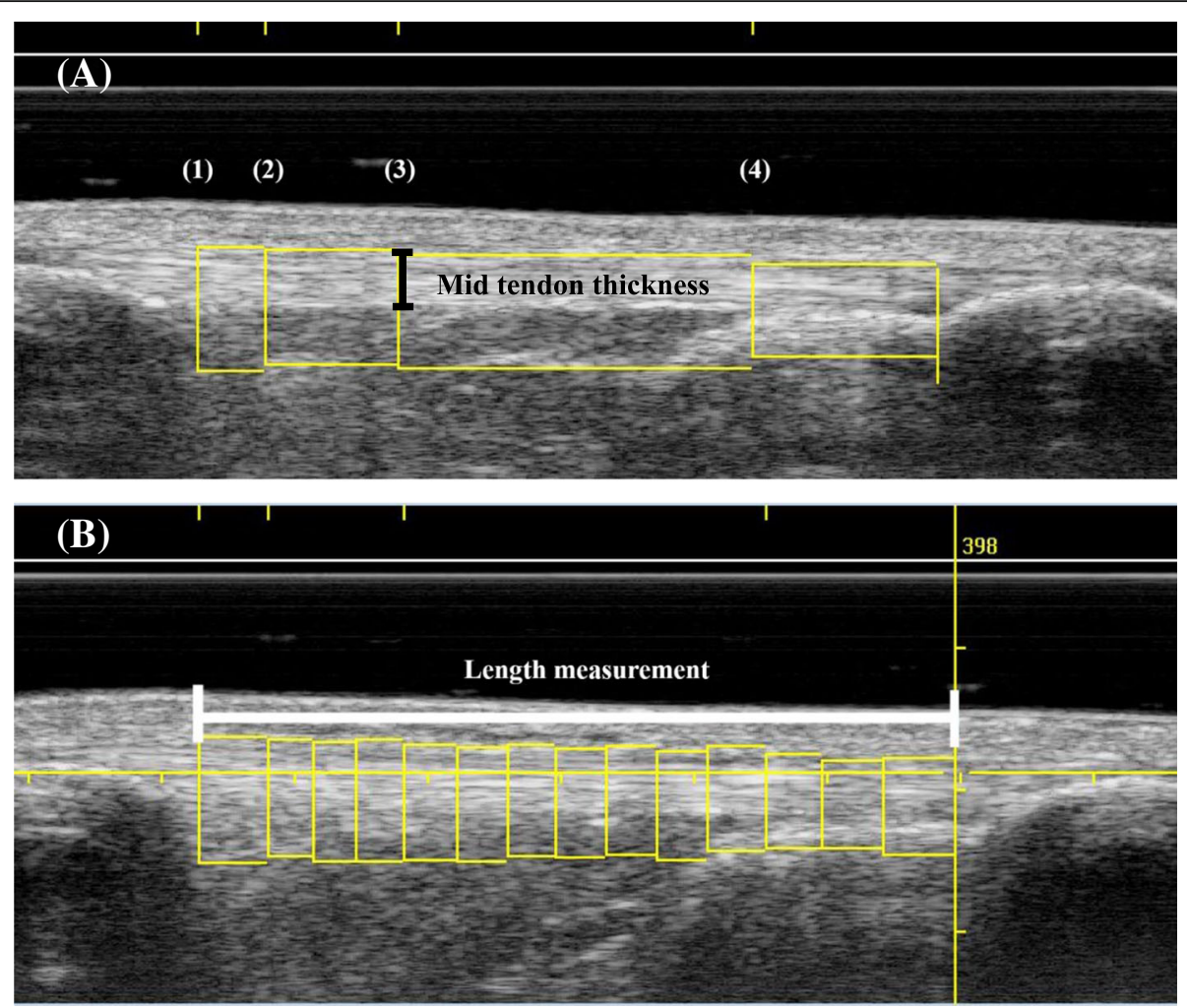

Fig. 5 Example of sagittal images of the patellar tendon after acquisition with UTC imaging. a The four areas of interest (1-4) are depicted. The vertical black bar shows the measurement of tendon thickness. The first area of interest (patella apex) was defined as the first image distal to the patella apex. The second area of interest (proximal tendon) started $0.52 \mathrm{~cm}$ distal to mark 1, and the third (mid tendon) $1.54 \mathrm{~cm}$ further distally. The fourth area of interest (distal tendon) was set at $75 \%$ of tendon length. $\mathbf{b}$ The length of the tendon is depicted by the horizontal white bar. In this case, 15 contours were drawn as shown. In all subjects a minimum of 10 of such contours were created. Each of these contours were individually marked in a transverse view to outline the extent of the tendon (see Fig. 4) for that area of interest

linear within the window, with little to no variation in their grayscale "whiteness" value. The echo-type II (blue) is reported in the presence of discontinuous, swollen, and wavy collagen bundles. It is defined by pixels that are aligned but display variation of about $10 \%$ of the gray levels. The echo-type III (red) is generated by a loose matrix consisting mainly of smaller fibrils. It is represented by much less aligned pixels with gray level variation of more than $10 \%$. The echo-type IV (black) is generated by mainly amorphous matrix with loose fibrils, cells and fluid (hematoma and exudate). It is represented by echoes with a severe lack of stability and no pixels alignment over sequential transverse images. [2, 3] In addition to echo-type characterization, the UTC algorithm also quantifies the area within the contour (volume) drawn in four selected areas of interested (reference marks 1-4).

After running the UTC software analyses, a range of raw data was exported for analysis.

The following variables were assessed: length of the patellar tendon; thickness of the mid tendon; percentage of echo-types I, II, III, and IV; tendon volume at patellar apex, proximal, mid, and distal tendon; and percentage of echo-types I, II, III and IV in the whole tendon.

\section{Repeated measures - intra-rater and inter-rater reliabilities}

Twenty unharvested and ten harvested patellar tendons from 18 participants were scanned and analyzed twice, 1 day apart, by the same examiner (C.S.P., physiotherapist -3 years of experience with UTC imaging acquisition and analysis) to test the intra-rater reliability of acquisition and analysis. Ten unharvested and eleven harvested (ACLR) patellar tendons from 16 participants were scanned, on the same day, by two different examiners (C.S.P. and R.C.G.S., sports physician -6 months of experience with UTC imaging acquisition and analysis) to investigate inter-rater reliability. For these tendons, each examiner analyzed their own scans to test the inter-rater reliability of the acquisition and the analysis. Additionally, nineteen unharvested and twenty harvested patellar tendons from 23 participants were analyzed by the two 
examiners (C.S.P. and R.C.G.S) to describe the interrater reliability of the analysis (Fig. 6).

\section{Statistical analysis}

Descriptive statistics (mean \pm standard deviation) were calculated for participants' demographics and all UTC variables. Data was tested for normality through visual inspection of histograms and Q-Q plots as well as calculation of Shapiro-Wilk statistics. The majority of the studied variables in harvested and unharvested tendons were normally distributed with exception of the following 9 variables: tendon thickness, percentage of echo-types III at proximal tendon, and percentage of echo-types III and IV at the distal tendon in harvested tendons, and the variables of percentage of echo-types I and II at mid-tendon, and percentage of echo-types III and IV in all areas of unharvested tendons. [27]

Test - retest reliability of both UTC data collection and analysis were assessed for harvested and unharvested patellar tendons. Two-way mixed single measures intra-class correlation for absolute agreement between repeated scans $\left(\mathrm{ICC}_{2,1}\right)$ was calculated to yield the standard error of the measurement $(\mathrm{SEM}=\mathrm{SD}($ Day 1$) \times[\sqrt{ }(1-\mathrm{ICC})]),[17,28]$ standard error of measurement as percentage of the grand mean $(\mathrm{SEM} \% \mathrm{GrM}=\mathrm{SEM} /$ Average Acquisitions $1 \& 2 \times$ 100 ), and the minimal detectable change of all UTC parameters $(\mathrm{MDC}=1.96 \times \mathrm{SEM} \times \sqrt{ } 2) . \quad[7,14,16,18,29,30]$ MDC for the variables of harvested and unharvested patellar tendons were calculated based on the intra-rater reliability analysis, when tendon scanning and contour drawing were performed two times by the same examiner (C.S.P.). ICC values were considered poor when less than 0.40 , fair between 0.40 and 0.59 , good between 0.60 and 0.74 , and excellent when above 0.75 . $[3,31] 95 \%$ confidence intervals (CI) are reported parenthetically after the group estimator where applicable. SPSS version 21 was used for all statistical analyses (SPSS Inc., Chicago, Illinois, USA).

\section{Results}

The mean age of the participants at the time of data acquisition was 23 years (range: 16 to 36 years), body mass of $75.9 \pm 15 \mathrm{~kg}$, and height of $177 \pm 11 \mathrm{~cm}$. The sport, the time of the data acquisition, and the type of graft used for the ACLR for each participant are detailed in Table 1.

\section{Repeated measures - intra-rater reliability}

Analysis to quantify the proportion of each of the echotypes (I, II, III and IV) in each of the areas of interest

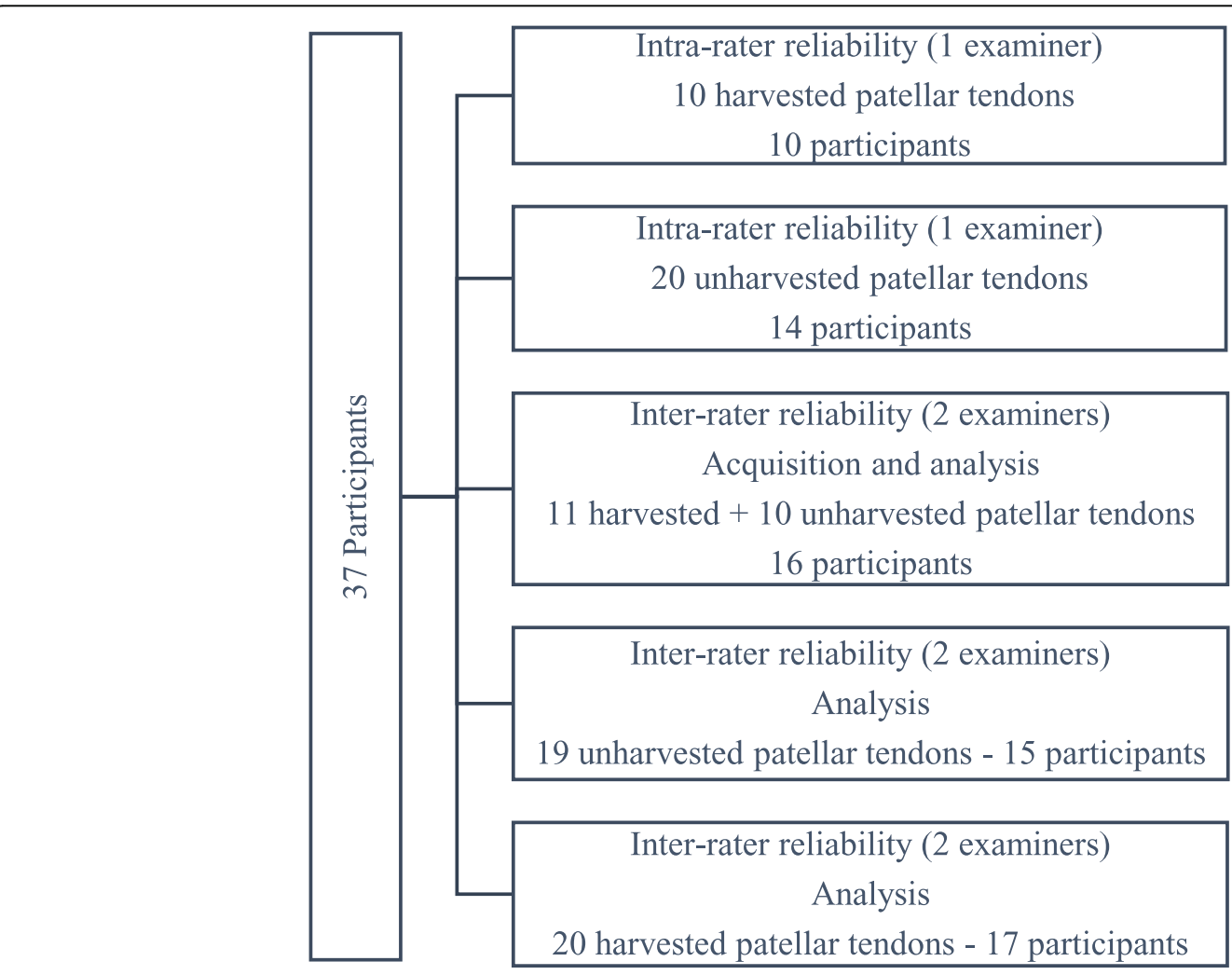

Fig. 6 Description of the number of patellar tendons and participants included, and the analyses performed 
(patellar apex, proximal tendon, mid tendon, distal tendon, and overall tendon) of harvested and unharvested patellar tendons displayed excellent intra-rater reliability ( $\mathrm{ICC}_{2,1}$ : 0.95-0.99 harvested, 0.89-0.98 unharvested) (Table 2). Intra-rater reliability for the measure of volume in the four areas of interest of the tendon was good $\left(\mathrm{ICC}_{2,1}: 0.69\right.$ harvested, 0.67 unharvested), and the intra-rater reliability for the measure of thickness of the mid tendon was excellent for harvested $\left(\mathrm{ICC}_{2,1}\right.$ : $0.88)$ but fair for unharvested $\left(\mathrm{ICC}_{2,1}: 0.57\right)$ tendons (Table 3). The measurement of tendon length displayed excellent intra-rater reliability $\left(4.5 \pm 0.6 \mathrm{~cm}, \mathrm{ICC}_{2,1}=\right.$ $0.79, \mathrm{SEM}=0.3 \mathrm{~cm}, \mathrm{SEM} \% \mathrm{GrM}=7.4 \%, \mathrm{MDC}=0.9$ $\mathrm{cm})$ for harvested tendons, and $\left(4.9 \pm 0.7 \mathrm{~cm}, \mathrm{ICC}_{2,1}=\right.$ $0.94, \mathrm{SEM}=0.2 \mathrm{~cm}, \mathrm{SEM} \% \mathrm{GrM}=3.6 \%, \mathrm{MDC}=0.5$ $\mathrm{cm})$ unharvested tendons.

The minimal detectable change for harvested tendons was $7.5 \%$ for echo-type I, $6.9 \%$ for echo-type II, $4.8 \%$ for echo-type III and $2 \%$ for echo-type IV. For unharvested tendons, the MDC was $14.1 \%$ for echo-type I, $10.6 \%$ for echo-type II, $6.3 \%$ for echo-type III and $1.2 \%$ for echo-type IV.

\section{Repeated measures - inter-rater reliability - acquisition and analysis}

Analysis of the amount of echo-types I, II, III and IV in the four areas of interest and in the overall tendon when two examiners acquired and analyzed their own scans of mixed harvested and unharvested patellar tendons demonstrated excellent inter-rater reliability $\left(\mathrm{ICC}_{2,1}: 0.89\right.$ 0.98) (Table 4). Volume of the tendon in the areas of interest, and thickness of the mid tendon showed good
$\left(\mathrm{ICC}_{2,1}: 0.67\right)$ and excellent $\left(\mathrm{ICC}_{2,1}: 0.97\right)$ inter-rater reliability, respectively (Table 5). The tendon length of mixed harvested and unharvested tendons appeared to have good inter-rater reliability $\left(4.5 \pm 0.5 \mathrm{~cm}, \mathrm{ICC}_{2,1}=\right.$ $0.63, \mathrm{SEM}=0.2 \mathrm{~cm}$, SEM \% GrM $=7.3 \%$ ).

\section{Repeated measures - inter-rater reliability - analysis}

When two examiners analyzed the same scan of harvested and unharvested tendons separately, the interrater reliability was excellent for the echo-type variables in the different areas of interest $\left(\mathrm{ICC}_{2,1}: 0.95-0.99\right)$ (Table 6) and mid tendon thickness of harvested tendons $\left(\mathrm{ICC}_{2,1}: 0.85\right)$ (Table 7). The inter-rater reliability of the volume in different levels of the tendon was fair for harvested $\left(\mathrm{ICC}_{2,1}: 0.59\right)$ and poor for unharvested $\left(\mathrm{ICC}_{2,1}\right.$ : 0.30 ) tendons (Table 7). Moreover, the mid tendon thickness of unharvested tendons also displayed poor interrater reliability $\left(\mathrm{ICC}_{2,1}: 0.24\right)$ when two examiners analyzed the same scan (Table 7). On the other hand, tendon length displayed excellent reliability for both harvested and unharvested tendons $\left(4.7 \pm 0.7 \mathrm{~cm}, \mathrm{ICC}_{2,1}=\right.$ $0.86, \mathrm{SEM}=0.3 \mathrm{~cm}, \mathrm{SEM} \% \mathrm{GrM}=5.4 \%$, and $4.8 \pm 0.6$ $\mathrm{cm}, \quad \mathrm{ICC}_{2,1}=0.79, \quad \mathrm{SEM}=0.3 \mathrm{~cm}, \quad \mathrm{SEM} \% \mathrm{GrM}=6.6 \%$ respectively).

\section{Discussion}

This is the first study to investigate the reliability of UTC in the measurement of tendon structure following ACLR. Results of the current study suggests that the UTC imaging displays excellent reliability for quantifying the proportion of each of the echo-types (I, II, III and IV) in each of the areas of interest (patellar apex,

Table 2 Echo-types values of harvested and unharvested tendons for the two acquisition days, done by one examiner

\begin{tabular}{|c|c|c|c|c|c|c|c|c|c|c|c|}
\hline \multicolumn{12}{|c|}{ Intra-rater reliability for acquisition and analysis - 1 examiner / 2 acquisitions/ 2 different days/ 2 analysis per patellar tendon } \\
\hline \multirow{2}{*}{$\begin{array}{l}\text { Examiner C.S.P. } \\
\text { Area/ Echo-types }\end{array}$} & \multicolumn{4}{|l|}{ DAY 1} & \multicolumn{4}{|l|}{ DAY 2} & \multirow[b]{2}{*}{ ICC (95\% Cl) } & \multirow[b]{2}{*}{$\begin{array}{l}\text { SEM (ICC) } \\
\% \text { GrM (\%) }\end{array}$} & \multirow[b]{2}{*}{$\begin{array}{l}\text { SEM } \\
\text { (ICC) }(\%\end{array}$} \\
\hline & Type I (\%) & Type II (\%) & Type III (\%) & Type IV (\%) & Type I (\%) & Type II (\%) & Type III (\%) & Type IV (\%) & & & \\
\hline \multicolumn{12}{|c|}{ Harvested patellar tendons of 10 participants $(n=10)$} \\
\hline Patellar Apex & $56.0 \pm 10.8$ & $33.5 \pm 5.9$ & $7.3 \pm 4.8$ & $2.9 \pm 1.6$ & $54.7 \pm 9.8$ & $31.6 \pm 6.9$ & $8.9 \pm 4.2$ & $4.8 \pm 2.6$ & $0.95(0.89-0.97)$ & 21.1 & 5.3 \\
\hline Proximal tendon & $60.0 \pm 6.6$ & $32.1 \pm 5.1$ & $5.8 \pm 3.9$ & $2.2 \pm 1.5$ & $60.5 \pm 8.8$ & $29.4 \pm 6.3$ & $6.6 \pm 4.1$ & $3.6 \pm 2.8$ & $0.97(0.94-0.98)$ & 16.1 & 4.0 \\
\hline Mid Tendon & $62.8 \pm 7.0$ & $29.4 \pm 4.0$ & $5.4 \pm 3.5$ & $2.5 \pm 1.7$ & $64.8 \pm 8.8$ & $27.2 \pm 6.8$ & $5.2 \pm 3.3$ & $3.1 \pm 2.6$ & $0.98(0.95-0.98)$ & 15.1 & 3.8 \\
\hline Distal Tendon & $46.9 \pm 7.9$ & $35.3 \pm 6.3$ & $13.2 \pm 8.4$ & $4.5 \pm 2.6$ & $50.0 \pm 12.6$ & $34.0 \pm 7.6$ & $11.4 \pm 5.8$ & $4.6 \pm 2.8$ & $0.95(0.89-0.97)$ & 17.2 & 4.3 \\
\hline Overall Tendon & $53.6 \pm 5.4$ & $33.3 \pm 4.1$ & $9.5 \pm 4.7$ & $3.7 \pm 1.7$ & $54.9 \pm 7.0$ & $31.6 \pm 4.5$ & $9.2 \pm 4.3$ & $4.1 \pm 2.4$ & $0.99(0.97-0.99)$ & 9.0 & 2.2 \\
\hline \multicolumn{12}{|c|}{ Unharvested patellar tendons of 14 participants $(n=20)$} \\
\hline Patellar Apex & $57.5 \pm 12.3$ & $39.0 \pm 10.6$ & $2.5 \pm 5.2$ & $0.9 \pm 1.9$ & $56.1 \pm 13.3$ & $40.5 \pm 12.0$ & $2.6 \pm 4.7$ & $0.8 \pm 1.6$ & $0.94(0.90-0.96)$ & 25.5 & 6.4 \\
\hline Proximal tendon & $65.7 \pm 10.3$ & $33.0 \pm 8.6$ & $0.8 \pm 2.3$ & $0.3 \pm 0.9$ & $67.4 \pm 8.5$ & $31.9 \pm 8.0$ & $0.5 \pm 0.9$ & $0.2 \pm 0.4$ & $0.97(0.94-0.97)$ & 21.0 & 5.2 \\
\hline Mid Tendon & $68.6 \pm 10.2$ & $30.1 \pm 8.7$ & $0.9 \pm 1.9$ & $0.3 \pm 0.7$ & $70.2 \pm 9.3$ & $29.0 \pm 8.6$ & $0.4 \pm 1.2$ & $0.2 \pm 0.5$ & $0.98(0.97-0.98)$ & 14.6 & 3.7 \\
\hline Distal Tendon & $53.3 \pm 10.1$ & $41.3 \pm 7.8$ & $4.3 \pm 5.6$ & $1.2 \pm 2.0$ & $52.9 \pm 17.7$ & $42.2 \pm 12.9$ & $4.1 \pm 9.3$ & $0.7 \pm 1.7$ & $0.89(0.83-0.92)$ & 31.6 & 7.9 \\
\hline Overall Tendon & $60.4 \pm 7.8$ & $35.2 \pm 6.3$ & $3.2 \pm 3.3$ & $0.8 \pm 1.2$ & $61.6 \pm 9.8$ & $33.9 \pm 6.9$ & $3.6 \pm 4.3$ & $0.8 \pm 1.2$ & $0.98(0.96-0.98)$ & 15.1 & 3.8 \\
\hline
\end{tabular}

$n=$ number of tendons assessed. Mean \pm standard deviation

ICC (95\% CI) Intra-class coefficient of reliability (95\% confidence interval), SEM \% GrM Standard error of measurement as percentage of the grand mean, SEM Standard error of measurement 
Table 3 Values of volume and thickness of harvested and unharvested tendons over two acquisition days, one examiner

\begin{tabular}{|c|c|c|c|c|}
\hline \multicolumn{5}{|c|}{ Intra-rater reliability for acquisition and analysis - 1 examiner / 2 acquisitions/ 2 different days/ 2 analysis per patellar tendon } \\
\hline \multicolumn{5}{|l|}{24 Participants } \\
\hline \multirow{2}{*}{$\begin{array}{l}\text { Examiner C.S.P. } \\
\text { Areas of interest }\end{array}$} & \multicolumn{2}{|c|}{ Harvested patellar tendon $(n=10)$} & \multicolumn{2}{|c|}{ Unharvested patellar tendon $(n=20)$} \\
\hline & Volume $\left(\mathrm{cm}^{3}\right)$ & Thickness (cm) & Volume $\left(\mathrm{cm}^{3}\right)$ & Thickness (cm) \\
\hline \multicolumn{5}{|l|}{ DAY 1} \\
\hline Patellar Apex & $1.4 \pm 0.3$ & NA & $1.0 \pm 0.2$ & NA \\
\hline Proximal tendon & $1.3 \pm 0.2$ & NA & $0.9 \pm 0.1$ & NA \\
\hline Mid Tendon & $1.3 \pm 0.2$ & $0.7 \pm 0.2$ & $0.9 \pm 0.2$ & $0.5 \pm 0.1$ \\
\hline Distal Tendon & $1.2 \pm 0.2$ & NA & $0.8 \pm 0.1$ & NA \\
\hline \multicolumn{5}{|l|}{ DAY 2} \\
\hline Patellar Apex & $1.4 \pm 0.2$ & NA & $1.0 \pm 0.2$ & NA \\
\hline Proximal tendon & $1.3 \pm 0.2$ & NA & $1.0 \pm 0.2$ & NA \\
\hline Mid Tendon & $1.2 \pm 0.2$ & $0.7 \pm 0.2$ & $0.9 \pm 0.2$ & $0.5 \pm 0.1$ \\
\hline Distal Tendon & $1.3 \pm 0.2$ & NA & $0.9 \pm 0.1$ & NA \\
\hline ICC (95\% Cl) & $0.69(0.48,-0.82)$ & $0.88(0.60,-0.96)$ & $0.67(0.52,-0.77)$ & $0.57(0.20,0.80)$ \\
\hline SEM (ICC) \% GrM & 10.6 & 8.9 & 10.2 & 8.7 \\
\hline SEM (ICC) & 0.1 & 0.1 & 0.1 & 0.04 \\
\hline MDC & 0.4 & 0.2 & 0.3 & 0.1 \\
\hline
\end{tabular}

$n=$ number of tendons assessed. Mean \pm standard deviation

ICC (95\% CI) Intra-class coefficient of reliability (95\% confidence interval), SEM \% GrM Standard error of measurement as percentage of the grand mean, SEM Standard error of measurement, MDC Minimal detectable change

proximal tendon, mid tendon, distal tendon, and overall tendon) and mid tendon thickness, and fair to good reliability for the measure of volume in all areas of interest of harvested patellar tendons. For unharvested patellar tendons, results suggest excellent reliability for the distribution of the four echo-types in all areas of interest, poor to good reliability for volume in the four selected areas, and poor to fair reliability for mid tendon thickness. Consequently, UTC may be a useful tool to characterize the quality of harvested patellar tendons after ACLR at different time points.

Results of the current study are in agreement with previous studies of normal and pathological Achilles [3, 7,
18] and patellar tendons [10, 26, 32], where excellent intra-rater reliability was found for the echo-types variables. Regardless of the examiners acquiring and analyzing different scans or different examiners analyzing the same scan, the intra- and inter-rater reliability for all the four echo-types in all areas of interest displayed excellent reliability for harvested and unharvested tendons, as well as mid tendon thickness of harvested patellar tendons and tendon length.

The reliability of the measure of mid tendon thickness (ICC ${ }_{2,1}: 0.85-0.88,0.7 \mathrm{~cm}$ harvested, $0.4-0.5 \mathrm{~cm}$ unharvested patellar tendons) compares favorably with the measurements of patellar tendon thickness observed by

Table 4 Echo-types values in harvested and unharvested tendons - performed by two examiners, each examiner taking two acquisitions on the same day

\begin{tabular}{|c|c|c|c|c|c|c|c|c|c|c|c|}
\hline \multicolumn{12}{|c|}{ Harvested and Unharvested patellar tendons of 16 participants - $(n=21)$} \\
\hline \multirow{2}{*}{$\begin{array}{l}\text { Area/ } \\
\text { Echo-types }\end{array}$} & \multicolumn{4}{|c|}{ Examiner 1 (C.S.P.) } & \multicolumn{4}{|c|}{ Examiner 2 (R.C.G.S.) } & \multirow[b]{2}{*}{ ICC $(95 \% \mathrm{Cl})$} & \multirow[b]{2}{*}{$\begin{array}{l}\text { SEM (ICC) } \\
\% \text { GrM (\%) }\end{array}$} & \multirow[b]{2}{*}{$\begin{array}{l}\text { SEM (ICC) } \\
(\%)\end{array}$} \\
\hline & Type I (\%) & Type II (\%) & Type III (\%) & Type IV (\%) & Type I (\%) & Type II (\%) & Type III (\%) & Type IV (\%) & & & \\
\hline Patellar Apex & $55.4 \pm 13.2$ & $31.0 \pm 8.2$ & $8.8 \pm 8.5$ & $4.8 \pm 5.0$ & $49.0 \pm 12.6$ & $36.3 \pm 8.5$ & $10.2 \pm 10.5$ & $4.5 \pm 5.0$ & $0.94(0.90,-0.96)$ & 25.5 & 6.4 \\
\hline Proximal tendon & $60.8 \pm 15.4$ & $27.0 \pm 8.8$ & $7.7 \pm 8.4$ & $4.6 \pm 5.3$ & $55.8 \pm 16.4$ & $30.5 \pm 6.1$ & $9.8 \pm 12.4$ & $4.0 \pm 4.9$ & $0.97(0.94,-0.97)$ & 21.0 & 5.2 \\
\hline Mid Tendon & $60.6 \pm 17.5$ & $26.4 \pm 9.3$ & $8.5 \pm 10.1$ & $4.5 \pm 4.6$ & $58.7 \pm 14.1$ & $29.2 \pm 7.0$ & $8.1 \pm 9.0$ & $4.0 \pm 5.8$ & $0.98(0.97,-0.98)$ & 14.6 & 3.7 \\
\hline Distal Tendon & $52.2 \pm 16.6$ & $26.2 \pm 9.6$ & $14.0 \pm 10.3$ & $7.4 \pm 6.0$ & $55.8 \pm 16.5$ & $28.1 \pm 6.3$ & $11.1 \pm 12.1$ & $5.2 \pm 4.6$ & $0.89(0.83,-0.92)$ & 31.6 & 7.9 \\
\hline Overall Tendon & $54.2 \pm 15.6$ & $25.4 \pm 7.9$ & $13.4 \pm 9.6$ & $7.1 \pm 5.4$ & $53.1 \pm 13.9$ & $29.2 \pm 4.9$ & $12.3 \pm 9.4$ & $5.6 \pm 4.4$ & $0.98(0.96,-0.98)$ & 15.1 & 3.8 \\
\hline
\end{tabular}


Table 5 Volume and thickness for harvested and unharvested tendons - two examiners taking two acquisitions on the same day

\begin{tabular}{|c|c|c|}
\hline Inter-rater reliability & ners/ 2 acquisitions & \\
\hline 6 Participants & & \\
\hline Harvested $(n=11) \mathrm{a}$ & ons & \\
\hline Areas of interest & Volume $\left(\mathrm{cm}^{3}\right)$ & Thickness $(\mathrm{cm})$ \\
\hline Examiner1 (C.S.P.) & & \\
\hline Patellar Apex & $1.1 \pm 0.4$ & NA \\
\hline Proximal tendon & $1.1 \pm 0.4$ & NA \\
\hline Mid Tendon & $1.0 \pm 0.3$ & $0.6 \pm 0.3$ \\
\hline Distal Tendon & $1.0 \pm 0.4$ & NA \\
\hline Examiner 2 (R.C.G.S.) & & \\
\hline Patellar Apex & $0.9 \pm 0.2$ & NA \\
\hline Proximal tendon & $1.0 \pm 0.2$ & NA \\
\hline Mid Tendon & $1.0 \pm 0.3$ & $0.6 \pm 0.2$ \\
\hline Distal Tendon & $1.0 \pm 0.3$ & NA \\
\hline ICC (95\% Cl) & $0.67(0.52,-0.77)$ & $0.97(0.91,-0.98)$ \\
\hline SEM (ICC) \% GrM & 10.2 & 7.8 \\
\hline SEM (ICC) & 0.1 & 0.05 \\
\hline
\end{tabular}

Hernandez et al., [26] who reported thickness of $0.5 \mathrm{~cm}$ at the mid tendon of basketball players, and with the Achilles tendon thickness observed by van Schie et al. [3] who reported reliability values of $\mathrm{ICC}=0.84$ and measurements of "anterior-posterior diameter" of $0.9 \mathrm{~cm}$ for symptomatic and $0.7 \mathrm{~cm}$ for asymptomatic Achilles tendons. However, despite the similar mean values obtained by each examiner, the very small standard error of measurement, and the comparable values with healthy patellar tendon thickness measured in previous studies $[33,34]$, the mid tendon thickness of unharvested tendons displayed poor inter-rater reliability. We suspect that this error may arise due to the precision of the measuring tool of the UTC imaging software. Specifically, this tool only reports to an accuracy of $0.1 \mathrm{~cm}$ within the 3-D constructed tendon block, and nearly all measures taken were either 0.4 or $0.5 \mathrm{~cm}$ for this value in the unharvested tendons. Thus, this variable was essentially dichotomous, and reliability should therefore be assessed with, say, percent agreement rather than intraclass correlation.

ICC values for tendon length measurement displayed good reliability values when harvested and unharvested tendons were analyzed together (ICC ${ }_{2,1}: 0.63,4.5 \pm 0.5$ $\mathrm{cm})$, and excellent reliability values when analyzed separately $\left(\mathrm{ICC}_{2,1}: 0.79,4.5 \pm 0.6 \mathrm{~cm}\right.$ harvested, $\mathrm{ICC}_{2,1}: 0.94$, $4.9 \pm 0.7 \mathrm{~cm}$ unharvested). Hernandez et al. [26] observed greater values of patellar tendon length in professional basketball players $(5.7 \pm 0.6 \mathrm{~cm})$, however they used the distance between patellar apex and the most prominent part of the tibial tuberosity to calculate the length of the patellar tendon measurement, instead of the notch of the tibia at the distal end as adopted in the current study.

Measurements for the tendon volume at different levels when the same examiner acquired and analyzed harvested and unharvested patellar tendons separately on separate days displayed good intra-rater reliability (ICC 2,1: 0.69 harvested, 0.67 unharvested). However, the inter-rater reliability for the same measurement ranged from poor to good over the different conditions. These findings can be partially explained by the methodology in acquiring this variable. The UTC algorithm calculates the volume based on the area of the contour that was manually drawn around the tendon by the examiner. How far within the tendon circumference one examiner decides to draw the contours affects the number of pixels within this area, thus the volume. However, a larger or smaller tendon circumference, does not affect the distribution of these pixels within the selected area.

It is important to highlight the small variability in the measurements of mid tendon thickness (approximately $0.1-0.2 \mathrm{~cm}$ ), and in the measurements of tendon volume displayed in unharvested tendons (approximately 0.2 $\mathrm{cm}^{3}$ ). We also note that mid tendon thickness and tendon volume results should be interpreted in light of the objectively small values of the observed SEM and MDC and are approximately $10 \%$ of the grand mean. $[28,35]$ These parameters allow better characterization of change over time after any intervention, and given these 
Table 6 Echo-type values in harvested and unharvested tendons - one acquisition made by one examiner with two examiners analyzing (the same scan data)

\begin{tabular}{|c|c|c|c|c|c|c|c|c|c|c|c|}
\hline \multirow[t]{2}{*}{ Area/ Echo-types } & \multicolumn{4}{|c|}{ Examiner 1 (C.S.P.) } & \multicolumn{4}{|c|}{ Examiner 2 (R.C.G.S.) } & \multirow[b]{2}{*}{ ICC (95\% Cl) } & \multirow[b]{2}{*}{$\begin{array}{l}\text { SEM (ICC) } \\
\% \text { GrM (\%) }\end{array}$} & \multirow[b]{2}{*}{$\begin{array}{l}\text { SEM } \\
\text { (ICC) (\% }\end{array}$} \\
\hline & Type I (\%) & Type II (\%) & Type III (\%) & Type IV (\%) & Type I (\%) & Type II (\%) & Type III (\%) & Type IV (\%) & & & \\
\hline \multicolumn{12}{|c|}{ Harvested patellar tendons of 17 participants $(n=20)$} \\
\hline Patellar Apex & $52.8 \pm 10.0$ & $31.3 \pm 6.3$ & $10.4 \pm 5.9$ & $5.4 \pm 3.5$ & $52.0 \pm 10.0$ & $32.3 \pm 6.9$ & $10.5 \pm 5.8$ & $5.3 \pm 3.0$ & $0.98(0.97,-0.98)$ & 10.5 & 2.6 \\
\hline Proximal tendon & $57.4 \pm 8.8$ & $29.4 \pm 4.8$ & $8.7 \pm 5.8$ & $4.7 \pm 4.0$ & $57.3 \pm 7.9$ & $29.3 \pm 5.0$ & $8.6 \pm 4.8$ & $4.8 \pm 3.2$ & $0.99(0.97,-0.99)$ & 10.4 & 2.6 \\
\hline Mid Tendon & $58.5 \pm 10.1$ & $28.1 \pm 4.8$ & $8.8 \pm 6.2$ & $5.0 \pm 3.9$ & $58.5 \pm 10.8$ & $29.0 \pm 7.3$ & $7.8 \pm 6.8$ & $4.9 \pm 4.7$ & $0.98(0.97,-0.98)$ & 11.3 & 2.8 \\
\hline Distal Tendon & $47.1 \pm 8.7$ & $29.3 \pm 8.6$ & $15.7 \pm 8.0$ & $7.9 \pm 5.2$ & $48.8 \pm 11.1$ & $30.5 \pm 9.1$ & $13.8 \pm 7.7$ & $7.1 \pm 5.1$ & $0.95(0.92,-0.96)$ & 15.2 & 3.8 \\
\hline Overall Tendon & $50.7 \pm 7.3$ & $28.7 \pm 5.8$ & $13.7 \pm 6.6$ & $7.1 \pm 4.5$ & $51.2 \pm 6.0$ & $29.9 \pm 5.5$ & $12.6 \pm 5.6$ & $6.6 \pm 4.0$ & $0.99(0.98,-0.99)$ & 6.8 & 1.7 \\
\hline \multicolumn{12}{|c|}{ Unharvested patella tendons of 15 participants $(n=19)$} \\
\hline Patellar Apex & $62.2 \pm 6.7$ & $36.6 \pm 6.2$ & $0.8 \pm 1.2$ & $0.3 \pm 0.5$ & $60.9 \pm 11.3$ & $37.3 \pm 10.4$ & $1.4 \pm 2.1$ & $0.4 \pm 1.0$ & $0.97(0.94-0.97)$ & 19.1 & 4.8 \\
\hline Proximal tendon & $70.2 \pm 5.6$ & $29.0 \pm 5.5$ & $0.4 \pm 0.8$ & $0.2 \pm 0.4$ & $68.3 \pm 6.9$ & $30.3 \pm 6.3$ & $0.9 \pm 1.3$ & $0.3 \pm 0.5$ & $0.99(0.98-0.99)$ & 12.8 & 3.2 \\
\hline Mid Tendon & $72.6 \pm 6.3$ & $26.5 \pm 6.6$ & $0.5 \pm 0.8$ & $0.2 \pm 0.5$ & $70.7 \pm 5.5$ & $27.4 \pm 5.2$ & $1.0 \pm 1.7$ & $0.6 \pm 1.2$ & $0.99(0.97-0.99)$ & 13.7 & 3.4 \\
\hline Distal Tendon & $58.3 \pm 10.9$ & $36.8 \pm 9.4$ & $3.7 \pm 3.9$ & $1.3 \pm 1.5$ & $57.9 \pm 10.0$ & $37.6 \pm 6.7$ & $3.3 \pm 4.7$ & $1.2 \pm 1.9$ & $0.95(0.91-0.96)$ & 23.0 & 5.8 \\
\hline Overall Tendon & $64.3 \pm 5.4$ & $31.4 \pm 5.4$ & $2.9 \pm 2.4$ & $1.1 \pm 1.2$ & $63.3 \pm 4.4$ & $33.0 \pm 4.1$ & $2.8 \pm 2.5$ & $1.1 \pm 1.1$ & $0.99(0.98-0.99)$ & 9.4 & 2.3 \\
\hline
\end{tabular}

$n=$ number of tendons assessed. Mean \pm standard deviation

ICC $(95 \% \mathrm{Cl})$ Intra-class coefficient of reliability ( $95 \%$ confidence interval), SEM \% GrM Standard error of measurement as percentage of the grand mean, SEM Standard error of measurement

results we recommend maintaining the same examiner for different measurements to minimize such errors.

Even though previous studies using UTC imaging have utilized different settings for analysis to quantify the proportion of echo-types of patellar tendons (window value of 25), the values of MDC observed for unharvested tendons are similar to previously published values even though the current study intentionally adopted a narrower window (17) for analysis allowing more detailed tendon tissue information. A recent reliability study in symptomatic and asymptomatic patellar tendons displayed MDC of $10.6 \%$ for echo-type I, $8.8 \%$ for echotype II, $3.7 \%$ for echo-type III, and $2.1 \%$ for echo-type IV [10], against the $14.1 \%$ for echo-type I, $10.6 \%$ for echotype II, $6.3 \%$ for echo-type III and $1.2 \%$ for echo-type IV calculated in this study for unharvested tendons. Interestingly, similar values of MDC were observed for harvested tendons $7.5 \%$ for echo-type I, $6.9 \%$ for echo-type II, $4.8 \%$ for echo-type III and $2 \%$ for echo-type IV.

Based on these results, future longitudinal studies could be implemented to explore possible associations of the characteristics of the patellar tendon with clinical symptoms at different time points following ACL surgery.

\section{Conclusions}

The minimum detectable change data reported here provides some normative population specific values to allow ultrasound tissue characterization to be employed to quantify the quality of patellar tendons following ACLR. This data can then better inform any longitudinal or comparative analyses.

\section{Key points Findings}

UTC imaging is a reliable tool to characterize the quality of harvested patellar tendons after ACLR and unharvested patellar tendons in patients following ACL injury.

This study provides a comprehensive description of the UTC methodology to assess and compare the quality of harvested and unharvested patellar tendons after ACL injury and/or ACLR.

\section{Implications}

UTC imaging can be used in longitudinal studies to explore the progression of the patellar tendon tissue's quality throughout the rehabilitation process after ACLR. Additionally, UTC imaging might be used in the future to explore possible associations of the tendon healing process with clinical symptoms at different time points following surgery.

\section{Caution}

This is the first study using UTC to assess harvested patellar tendons after ACLR, and some aspects of the methodology used to assess the quality of these tendons differ from the methodology used for unharvested tendons. For instance, the tibial notch is not always centralized due to the harvested bone plug removed from the tibial tuberosity, and data of the distal portion of the tendon was included. Moreover, window size 17 was chosen for analysis for more detailed information of these harvested tendons rather than window size 25 as is more frequently reported. Thus, when comparing data 
Table 7 Values of volume and thickness in harvested and unharvested patellar tendons - one acquisition, two examiners

\begin{tabular}{|c|c|c|c|c|}
\hline \multicolumn{5}{|c|}{ Inter-rater reliability of analysis - 1 acquisition/ 1 day/ 2 examiners/ 2 analysis per patellar tendon } \\
\hline \multicolumn{5}{|l|}{23 Participants } \\
\hline \multirow[t]{2}{*}{ Areas of interest } & \multicolumn{2}{|c|}{ Harvested patellar tendons $(n=20)$} & \multicolumn{2}{|c|}{ Unharvested patellar tendons $(n=19)$} \\
\hline & Volume $\left(\mathrm{cm}^{3}\right)$ & Thickness $(\mathrm{cm})$ & Volume $\left(\mathrm{cm}^{3}\right)$ & Thickness $(\mathrm{cm})$ \\
\hline \multicolumn{5}{|l|}{ Examiner 1 (C.S.P.) } \\
\hline Patellar Apex & $1.5 \pm 0.3$ & NA & $0.9 \pm 0.2$ & NA \\
\hline Proximal tendon & $1.4 \pm 0.4$ & NA & $0.9 \pm 0.1$ & NA \\
\hline Mid Tendon & $1.3 \pm 0.3$ & $0.7 \pm 0.2$ & $0.9 \pm 0.1$ & $0.4 \pm 0.1$ \\
\hline Distal Tendon & $1.3 \pm 0.3$ & NA & $0.8 \pm 0.2$ & NA \\
\hline \multicolumn{5}{|l|}{ Examiner 2 (R.C.G.S.) } \\
\hline Patellar Apex & $1.2 \pm 0.3$ & NA & $0.9 \pm 0.2$ & NA \\
\hline Proximal tendon & $1.3 \pm 0.3$ & NA & $0.9 \pm 0.2$ & NA \\
\hline Mid Tendon & $1.4 \pm 0.3$ & $0.7 \pm 0.2$ & $1.0 \pm 0.3$ & $0.4 \pm 0.0$ \\
\hline Distal Tendon & $1.4 \pm 0.2$ & NA & $0.9 \pm 0.2$ & NA \\
\hline ICC (95\% Cl) & $0.59(0.42,-0.71)$ & $0.85(0.66,0.94)$ & $0.30(0.08,-0.49)$ & $0.24(-0.20,0.62)$ \\
\hline SEM (ICC) \% GrM & 16.4 & 13.9 & 14.6 & 13.5 \\
\hline SEM (ICC) & 0.2 & 0.1 & 0.1 & 0.1 \\
\hline
\end{tabular}

$n=$ number of tendons assessed. Mean \pm standard deviation

ICC (95\% CI) Intra-class coefficient of reliability (95\% confidence interval), SEM \% GrM Standard error of measurement as percentage of the grand mean, SEM

Standard error of measurement

of different studies, this difference in analysis setting should be considered.

For assessing the measurement of tendon volume over time, it is advisable that a single examiner follows the same patient throughout the period of interest.

Additional validation studies in humans are likely required to verify the echo-types classified by UTC have the same validity as those documented in horses. Finally, it should be noted that despite the growing popularity of imaging modalities in clinical practice, the relative cost of UTC imaging might be a limitation to its widespread clinical adoption.

\section{Abbreviations}

ACL: Anterior cruciate ligament; ACLR: Anterior cruciate ligament reconstruction; BTB: Bone tendon bone graft; Hst: Hamstring graft; ICC: Intraclass correlation; M: Months post-operative; MDC: Minimal detectable change; Post-op: Post-operative; SD: Standard deviation; SEM \% GrM: Standard error of measurement as percentage of the grand mean; SEM: Standard error of measurement; US: Ultrasound; UTC: Ultrasound tissue characterization; W: Weeks post-operative; Y: Years post-operative

\section{Acknowledgements}

Authors would like to thank our colleagues from the ACL Ax Center and ACL Rehabilitation of Aspetar: Argyro Kotsifaki, Bart Sas, Carla de Paula, Dustin Maree, Jaleleddine Belhaj, Jasenko Klauznicer, Kosntantinos Defteraios, Martina Jakob Emeršič, Mansour Otayek, Mayolo Camacho, Mirna Anadani, Paul Read, Riadh Miladi, Sean McAuliffe, Theodosia Palli, and Vasileios Sideris for all the contribution and support.

\section{Authors' contributions}

CSP was responsible for the conception and design of the study, acquisition, analysis and interpretation of data, in drafting the manuscript, and agreed to be accountable for all aspects of this research. RCGS made substantial contributions to the acquisition, analysis and interpretation of data, reviewed it critically for important intellectual content, and agreed to be accountable for all aspects of this research. RW made substantial contributions to conception and design of this study, reviewed it critically for important intellectual content, gave final approval of the version to be published, and agreed to be accountable for all aspects of this research. TF made substantial contributions to conception and design of this study, reviewed it critically for important intellectual content, gave final approval of the version to be published, and agreed to be accountable for all aspects of this research. All authors read and approved the final manuscript.

\section{Authors' information}

C.S.P. Physical therapist, MSc, Rehabilitation Department - ASPETAR Orthopedic and Sports hospital, Doha, Qatar, and PhD candidate, Faculty of Sport and Health Sciences, Biology of Physical Activity, Neuromuscular Research Center, University of Jyväskylä, Jyväskylä, Finland. carla. pereira@aspetar.com

R.C.G.S. Sports Physician, ASPETAR Orthopedic and Sports hospital, Doha, Qatar.rafael.santos@aspetar.com

R. W. Assistant Director of Clinical Projects \& Quality, Physical therapist, PhD, Rehabilitation Department - ASPETAR Orthopedic and Sports hospital, Doha, Qatar.rodney.whiteley@aspetar.com

T.F. Professor of Kinesiology, PhD, Faculty of Sport and Health Sciences, Biology of Physical Activity, Neuromuscular Research Center, University of Jyväskylä, Jyväskylä, Finland. taija.finni@jyu.fi

\section{Funding}

The publication of this article was funded by the Qatar National Library.

\section{Availability of data and materials}

The datasets used and analyzed during the current study are available from the correspondent author on reasonable request.

Ethics approval and consent to participate

The study protocol was approved by ethical committee of the Anti-Doping Laboratory Qatar Research Office (2017000227).

Written informed consent was obtained from each participant or legal guardian.

Consent for publication

Not applicable. 


\section{Competing interests}

The authors declare that they have no competing interests.

Received: 31 October 2018 Accepted: 24 June 2019 Published online: 19 July 2019

\section{References}

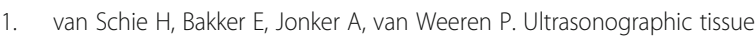
characterization of equine superficial digital flexor tendons by means of gray level statistics. Am J Vet Res. 2000;61:210-9.

2. van Schie $H$, Bakker $E$, Jonker $A$, van Weeren $P$. Computerized ultrasonographic tissue characterization of equine superficial digital flexor tendons by means of stability quantification of echo patterns in contiguous transverse ultrasonographic images. Am J Vet Res. 2003;64:366-75.

3. van Schie H, de Vos R, de Jonge S, Bakker E, Heijboer M, Verhaar J, et al. Ultrasonographic tissue characterisation of human Achilles tendons: quantification of tendon structure through a novel non-invasive approach. Br J Sports Med. 2010;44:1153-9.

4. de Vos R, Weir A, Tol J, Verhaar J, Weinans $H$, van Schie $H$. No effects of PRP on ultrasonographic tendon structure and neovascularisation in chronic midportion Achilles tendinopathy. Br J Sports Med. 2011;45:387-92.

5. de Vos R, Heijboer M, Weinans H, Verhaar J, van Schie H. Tendon Structure's lack of relation to clinical outcome after eccentric exercises in chronic Midportion Achilles tendinopathy. J Sport Rehabil. 2012;21:34-43.

6. van Schie H, Docking S, Daffy J, Praet S, Rosengarten S, Cook J. Ultrasound tissue characterisation, an innovative technique for injury-prevention and monitoring of tendinopathy. Br J Sports Med. 2013;47:14.

7. Docking SI, Rosengarten SD, Daffy J, Cook J. Structural integrity is decreased in both Achilles tendons in people with unilateral Achilles tendinopathy. J Sci Med Sport. 2015;18:383-7. https://doi.org/10.1016/j.jsams.2014.06.004.

8. Rudavsky A, Cook JL, Docking S. Proximal patellar tendon pathology can develop during adolescence in young ballet dancers- a 2 year longitudinal study. Scand J Med Sci Sports. 2018;28:2035-41.

9. van Schie H, Bakker E, Cherdchutham W, Jonker A, van de Lest C, van Weeren P. Monitoring of the repair process of surgically created lesions in equine superficial digital flexor tendons by use of computerized ultrasonography. Am J Vet Res. 2009;70:37-48.

10. van Ark M, Maciel Rabello L, Hoevenaars D, Meijerink J, van Gelderen N, Zwerver J, et al. Inter- and intra-rater reliability of ultrasound tissue characterization ( $<\mathrm{scp}>\mathrm{UTC}</ \mathrm{scp}>$ ) in patellar tendons. Scand J Med Sci Sports. 2019;sms.13439. https://doi.org/10.1111/sms.13439.

11. Docking S, Rosengarten S, Daffy J, Cook J. Treat the donut, not the hole: the pathological Achilles and patellar tendon has sufficient amounts normal tendon structure. J Sci Med Sport. 2014;18:e2. https://doi.org/10.1016/j. jsams.2014.11.015.

12. Drew BT, Smith TO, Littlewood C, Sturrock B, Drew BT. Do structural changes (eg, collagen/matrix) explain the response to therapeutic exercises in tendinopathy: a systematic review. Br J Sports Med. 2014;48:966-72.

13. Cook JL, Rio E, Purdam CR, Docking SI. Revisiting the continuum model of tendon pathology: what is its merit in clinical practice and research? $\mathrm{Br}$ J Sports Med. 2016;50:1187-91

14. de Jonge $\mathrm{S}, \mathrm{Tol} J \mathrm{~L}$, Weir $\mathrm{A}$. The tendon structure returns to asymptomatic values in nonoperatively treated Achilles tendinopathy but is not associated with symptoms. Am J Sports Med. 2015:43:2950-8.

15. Docking SI, van Schie J, Daffy J, Rosengarten S, Cook JL. Bilateral changes in unilateral achilles tendinopathy quantified using ultrasound tissue characterisation. Br J Sports Med. 2013;47:2013.

16. Wezenbeek E, Mahieu N, Willems T, Van Tiggelen D, De Muynck M, De Clercq D, et al. What does normal tendon structure look like? New insights into tissue characterization in the Achilles tendon. Scand J Med Sci Sports. 2017;27:746-53. https://doi.org/10.1111/sms.12706.

17. Docking SI, Ooi CC, Connell D. Tendinopathy: is imaging telling us the entire story? J Orthop Sports Phys Ther. 2015:45:842-52. https://doi.org/10. 2519/jospt.2015.5880.

18. Docking SI, Cook J. Pathological tendons maintain sufficient aligned fibrillar structure on ultrasound tissue characterization (UTC). Scand J Med Sci Sports. 2016;26:675-83.

19. Wong AMY, Docking SI, Cook JL, Gaida JE. Does type 1 diabetes mellitus affect Achilles tendon response to a $10 \mathrm{~km}$ run? A case control study. BMC Musculoskelet Disord. 2015;16:345. https://doi.org/10.1186/s12891-015-0803-z.
20. Vaishya R, Agarwal AK, Ingole S, Vijay V. Current trends in anterior cruciate ligament reconstruction: a review. Curēus. 2015;7:e378. https://doi.org/10. 7759/cureus.378

21. Shelbourne KD, Stube KC. Anterior cruciate ligament (ACL)-deficient knee with degenerative arthrosis: treatment with an isolated autogenous patellar tendon ACL reconstruction. Knee Surg Sports Traumatol Arthrosc. 1997;5:150-6.

22. Yunes M, Richmond JC, Engels EA, Pincweski LA. Patellar versus hamstring tendons in anterior cruciate ligament reconstruction: a meta-analysis. Arthroscopy. 2001;17:248-57.

23. Lautamies R, Harilainen A, Kettunen J, Sandelin J, Kujala UM. Isokinetic quadriceps and hamstring muscle strength and knee function 5 years after anterior cruciate ligament reconstruction: comparison between bonepatellar tendon-bone and hamstring tendon autografts. Knee Surg Sports Traumatol Arthrosc. 2008;16:1009-16.

24. Mastrokalos DS, Springer J, Siebold R, Paessler HH. Donor site morbidity and return to the preinjury activity level after anterior cruciate ligament reconstruction using ipsilateral and contralateral patellar tendon autograft: a retrospective, nonrandomized study. Am J Sports Med. 2005;33:85-93.

25. Marumoto J, Mitsunaga M, Richardson A, Medoff R, Mayfield G. Late patellar tendon ruptures after removal of the central third for anterior cruciate ligament reconstruction of two cases. Am J Sports Med. 1996;24:698-701.

26. Hernández G, Domínguez D, Moreno J, Til L, Capdevila L. Patellar tendon analysis by ultrasound tissue characterization; comparison between professional and amateur basketball players. Asymptomatic versus symptomatic. Apunt Med l'Esport. 2017;52:45-52.

27. Hays WL. Statistics. 4th ed. Fort Worth: Holt, Rinehart \& Winston Inc.e; 1988.

28. Denegar CR, Ball DW. Assessing reliability and precision of measurement: an introduction to Intraclass correlation and standard error of measurement Intraclass correlation and standard error of measurement. J Sport Rehabil. 1993:2:35-42.

29. Beckerman H, Roebroeck ME, Lankhorst GJ, Becher JG, Bezemer PD, Verbeek ALM. Smallest real difference, a link between reproducibility and responsiveness. Qual Life Res. 2001;10:571-8.

30. Rosengarten SD, Cook JL, Bryant AL, Cordy JT, Daffy J, Docking SI. Australian football players' Achilles tendons respond to game loads within 2 days: an ultrasound tissue characterisation (UTC) study. Br J Sports Med. 2015:49:1837. https://doi.org/10.1136/bjsports-2013-092713.

31. Cicchetti D. Guidelines, criteria, and rules of thumb for evaluating normed and standardized assessment instruments in psychology. Psychol Assess. 1994;6:284-90.

32. van Ark M, Docking S, Rudavsky A, Rio E, Zwerver J, Cook JL, et al. Does the adolescent patellar tendon respond to 5 days of cumulative load during a volleyball tournament? Scand J Med Sci Sports. 2016;26:189-96.

33. Rudavsky A, Cook J, Docking S. Quantifying proximal patellar tendon changes during adolescence in elite ballet dancers, a 2-year study. Scand J Med Sci Sports. 2018:28:2369-74.

34. Kulig K, Landel R, Chang YJ, Hannanvash N, Reischl SF, Song P, et al. Patellar tendon morphology in volleyball athletes with and without patellar tendinopathy. Scand J Med Sci Sports. 2013;23:81-8.

35. Koo TK, Li MY. A guideline of selecting and reporting Intraclass correlation coefficients for reliability research. J Chiropr Med. 2016;15:155-63. https:// doi.org/10.1016/j.jcm.2016.02.012

\section{Publisher's Note}

Springer Nature remains neutral with regard to jurisdictional claims in published maps and institutional affiliations.

Ready to submit your research? Choose BMC and benefit from:

- fast, convenient online submission

- thorough peer review by experienced researchers in your field

- rapid publication on acceptance

- support for research data, including large and complex data types

- gold Open Access which fosters wider collaboration and increased citations

- maximum visibility for your research: over $100 \mathrm{M}$ website views per year

At BMC, research is always in progress.

Learn more biomedcentral.com/submissions 